\title{
Accidental endoscopic piercing of the tongue with an Ovesco clip
}

A 77-year-old woman was sent to our center for radiological investigation of a suspect pancreatic lesion. A computed tomography (CT) scan with contrast had been performed of a malignant pancreatic neoplasia invading mesenteric vessels and conditioning jaundice. Under deep sedation with intravenous propofol (Diprivan; Astra Zeneca, Wilmington, Delaware, North Carolina, USA), the patient underwent endoscopic ultrasound to stage the lesion. During the passage of the endoscope between the stomach and duodenum, we observed a $15-\mathrm{mm}$ diameter, full-thickness lesion on the posterior wall of the duodenal bulb, just above the duodenal knee.

Using an operative gastroscope (Pentax EG 3490K; Pentax, Hamburg, Germany), we tried to place on the perforation an 11-mm clip with sharp teeth (Ovesco Endoscopy, Tübingen, Germany) but, during the passage of the mouthpiece, the clips

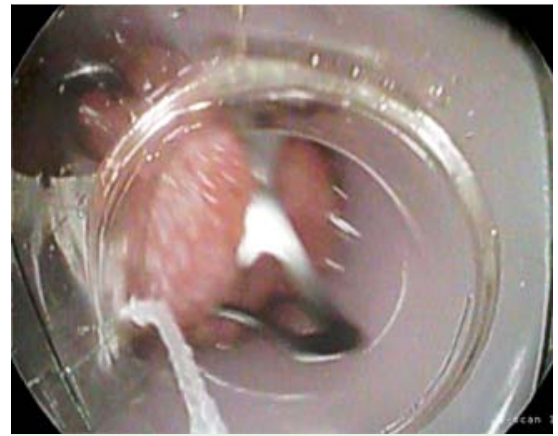

Fig. 1 Ovesco clip accidentally released on the tongue.

were accidentally released on the tongue ( Fig. 1). This was probably due to too much thread tension release. The clip was immediately removed manually.

Endoscopy_UCTN_Code_CPL_1AH_2AJ

Competing interests: None

\section{B. Mangiavillano, E. Morandi, E. Masci}

Gastrointestinal Endoscopy; Azienda Ospedaliera San Paolo - University Hospital, University of Milan, Milan

\section{Bibliography}

DOI http://dx.doi.org/

10.1055/s-0032-1309354

Endoscopy 2012; 44: E221

(c) Georg Thieme Verlag KG

Stuttgart · New York

ISSN 0013-726X

\section{Corresponding author}

\section{B. Mangiavillano, MD}

Gastrointestinal Endoscopy

Azienda Ospedaliera San Paolo - University Hospital, University of Milan

8 Via A. di Rudinì

20142 Milano

Italy

Fax: +39-02-81844647

b_mangiavillano@hotmail.com 